\title{
Civilisations
}

Revue internationale d'anthropologie et de sciences

humaines

$57 \mid 2008$

Tourisme, mobilités et altérités contemporaines

\section{Une légende à des fins touristiques dans la Roumanie communiste}

Les circuits à thème « Dracula, Vérité et Légende »

Mihaela Hainagiu

\section{(2) OpenEdition}

Journals

Édition électronique

URL : https://journals.openedition.org/civilisations/1154

DOI : $10.4000 /$ civilisations. 1154

ISSN : 2032-0442

Éditeur

Institut de sociologie de l'Université Libre de Bruxelles

Édition imprimée

Date de publication : 29 décembre 2008

Pagination : 109-125

ISBN : 2-87263-022-8

ISSN : 0009-8140

Référence électronique

Mihaela Hainagiu, «Une légende à des fins touristiques dans la Roumanie communiste », Civilisations [En ligne], 57 | 2008, mis en ligne le 29 décembre 2011, consulté le 21 septembre 2021. URL : http:// journals.openedition.org/civilisations/1154; DOI : https://doi.org/10.4000/civilisations.1154

(c) Tous droits réservés 


\title{
1. Écrire le mythe, réécrire l'histoire
}

\section{Une légende à des fins touristiques dans la Roumanie communiste Les circuits à thème "Dracula, Vérité et Légende "}

\author{
Mihaela HAINAGIU
}

\begin{abstract}
Résumé : Croisant et recroisant motifs littéraires, historiques, filmiques avec des éléments patrimoniaux, jouant constamment sur les frontières entre le vrai et le faux, juxtaposant folklore et archives, le tourisme américain des années 1970 assura, autour du personnage de Dracula, la promotion d'un nouveau lieu touristique, susceptible d'attirer le public américain : la Roumanie et tout particulièrement la Transylvanie, terre du vampire Dracula. Face à l'intérêt touristique américaine, véritable opportunité pour asseoir un secteur touristique international roumain, quelles réponses ont été données par le régime communiste de Nicolae Ceausescu? À partir de l'étude des circuits "Dracula, Vérité et Légende », mis en place par le ministère du Tourisme roumain au milieu des années 1970, cet article analyse comment le régime de Nicolae Ceausescu a constitué ce type de tourisme en enjeu, et les usages qui en ont été faits. On montrera, dans un premier temps, que, à l'époque communiste, le secteur touristique a une mission patriotique chargée d'élaborer et de diffuser une identité nationale, conciliable avec le communisme. Dans un second temps, on s'attachera à mettre en évidence les limites de cette politisation du tourisme.
\end{abstract}

Mots-clés : tourisme, Roumanie, Dracula, nationalisme.

Abstract: Touristic expansion is correlated with patrimonial practices, and a historical or political motif, a literary myth can be thus incarnated in a real area or an imaginary place. This is the case with the "Myth of Dracula": by crossing and recrossing. Interweaving literary, filmic and historical allusions, with patrimonial elements, playing constantly on the boundary between true and false, combining folklore and archives, American tourism promoted in the 1970s, around the personage of Dracula, a new touristic site supposed to attract the American public: Romania, and in particular Transylvania, country of the vampire Dracula. In face of this American touristic interest, which offered a real opportunity to establish a Romanian international touristic activity, what were the answers given by the communist regime of Nicolae Ceausescu? Based on the study of the circuits "Dracula, the Truth and the Legend", conceived by the Romanian ministry of Tourism in the middle 1970s, this article analyses how Nicolae Ceausescu's regime transformed and used this tourism. In the first section of the paper, I will show that, during the communist period, the touristic sector has a patriotic mission responsible for the elaboration and the diffusion of a national identity compatible with communism. Second, I will try to emphasize the limits of this politization of tourism.

Key words: tourism, Romania, Dracula, nationalism. 


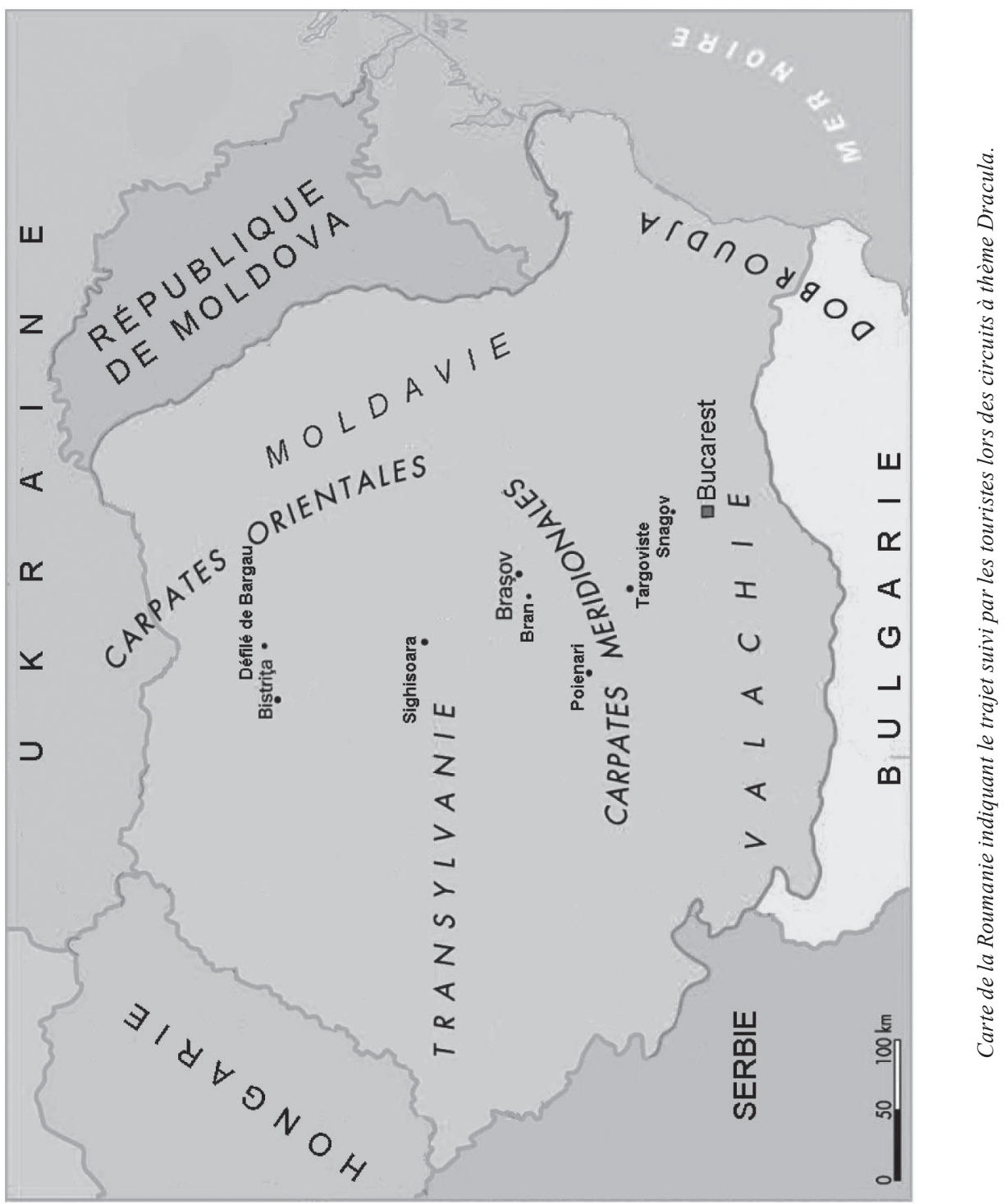


L

'histoire du tourisme est faite de l'invention incessante de nouvelles pratiques touristiques et de mises en scènes de nouveaux lieux (Boyer 2002). Rendre attractif un nouveau lieu, c'est souvent le doter d'une histoire inspirée de travaux d'ethnologie et de littérature pour piquer l'intérêt et alimenter la curiosité des publics. Dans de nombreux pays, l'expansion du tourisme est ainsi corrélée à des usages patrimoniaux et un motif historique ou politique, un mythe littéraire peuvent ainsi s'incarner dans un lieu ou un espace imaginaire. Tel est le cas du mythe de Dracula et des usages qu'ont pu en faire les entrepreneurs de tourisme tant aux États-Unis qu'en Roumanie ${ }^{1}$.

Au tournant des années 1970, le comte vampire Dracula, personnage issu du roman de Bram Stoker ${ }^{2}$ et de nombreux films américains, est reconverti en motif touristique. Inspiré à la fois de la fiction littéraire et filmique et d'un travail proprement historique (Florescu et McNally 1972) insérant Dracula dans une filiation attestée avec un voïévode valaque ${ }^{3}$ du $15^{\mathrm{e}}$ siècle (Vlad l'Empaleur, connu également sous le sobriquet de « Drăculea $\left.{ }^{4} »\right)$, un personnage flamboyant du nom de Dracula émerge progressivement. Croisant et recroisant motifs littéraires, historiques, filmiques, avec des éléments patrimoniaux, jouant constamment sur les frontières entre le vrai et le faux, juxtaposant folklore et archives, l'industrie touristique américaine de cette période assura la promotion d'un nouveau lieu susceptible d'attirer le public : la Roumanie et tout particulièrement la Transylvanie, terre du vampire Dracula. L'étrangeté, voire l'exotisme d'un tel lieu pour un public américain se conjugue avec une sorte d'attraction apeurée à l'égard d'un pays aux frontières fermées appartenant « au bloc communiste », à l'époque de la guerre froide.

De son côté, la Roumanie communiste privilégie à cette époque un tourisme centré essentiellement sur l'espace national (Istrate et al. 1996, cité in Muresan et al. 1998). Le secteur international du tourisme roumain, censé prendre en charge les visiteurs américains susceptibles de venir en Roumanie « à la recherche de Dracula », est peu développé, en raison notamment de la politique de restrictions et de surveillance des étrangers, de la peur de leurs possibles ingérences dans les affaires de l'État, mais également à cause de la priorité accordée à d'autres secteurs de l'économie nationale (Muresan et al. 1998 : 74).

Face à l'offre touristique américaine, véritable opportunité pour asseoir un secteur touristique international roumain, quelles réponses ont été données par le régime communiste de Nicolae Ceausescu ? Cette question est d'autant plus légitime qu'elle

1. Je remercie Rose-Marie Lagrave, Lucian Daramus, les lecteurs anonymes de Civilisations et les coordinateurs de ce numéro pour la lecture attentive de cet article. Je tiens également à remercier ici Anne-Marie Thiesse, Gabrielle Schütz, J.S. Eideliman et Laure Lacan pour les commentaires sur la première version de ce texte et Vintila Mihailescu pour des premiers débats sur le tourisme de Dracula. Toutefois, l'analyse faite ici n'engage que son auteur.

2. Bram Stoker, 1897 , Dracula, London, $1^{\text {ère }}$ edition.

3. Le voïvode est un prince, un souverain d'une principauté, dans les pays d'Europe centrale. La Valachie est, au $15^{\mathrm{e}}$ siècle, une principauté située sur le cours inférieur du Danube et, de nos jours, une région de la Roumanie.

4. C'est le père de Vlad l'Empaleur qui, en 1431, a pris le nom de Dracul quand il a été inclus dans l'Ordre des Dragons. «Drăculea » est le sobriquet attribuée à Vlad 1'Empaleur au Moyen Age, qui « signifiait simplement « le fils de Dracul » et était utilisé pour distinguer Vlad l'Empaleur de son père » (Light 2007 : 750 ). 
s'inscrit dans un moment de réécriture de l'histoire nationale roumaine et de célébration des vertus patriotiques de Nicolae Ceausescu à travers la commémoration des chefs d'État qui l'ont précédé (Boia 1997 et Dragusanu 2002). Érigés en « héros nationaux » par le pouvoir, ces derniers constituent un Panthéon dans lequel Ceausescu sera l'ultime consécration. Il était par conséquent nécessaire de concilier un projet politique de construction de la Nation communiste dans lequel figure en bonne place Vlad l'Empaleur - ce qui était par ailleurs le cas au $19^{\mathrm{e}}$ siècle, au moment de la création d'une conscience nationale des Roumains - et la possibilité de développement d'un secteur d'activité touristique aux fortes retombées économiques, représentée par l'offre américaine qui érige le héros national Vlad l'Empaleur en Comte vampire Dracula.

À partir de l'étude des circuits «Dracula, Vérité et Légende ${ }^{5}$, mise en place par le ministère du Tourisme roumain au milieu des années 1970, cet article analyse les enjeux de ce type de tourisme pour le régime de Nicolae Ceausescu et les usages qui en ont été faits. On montrera, dans un premier temps, que durant cette période, le secteur touristique est redevable d'une mission patriotique chargée d'élaborer et de diffuser une identité nationale, conciliable avec le communisme. Si de nombreux travaux sur la construction de la Nation roumaine à l'époque communiste ont analysé les écrits des intellectuels (Verdery 1991), le folklore (Karnoouh 1990), l'historiographie (Verdery 1991) ou les commémorations (Dragusanu 2002) pour mettre au jour la dimension politique qu'ils recèlent, le secteur touristique a échappé à cette lecture ${ }^{6}$. Or il apporte une contribution complémentaire à cette entreprise. Dans un second temps, on s'attachera à mettre en évidence les limites (notamment en termes d'attraction des touristes étrangers sur une longue durée) d'une réappropriation politique du motif Dracula en Roumanie au profit d'une fuite dans l'imaginaire.

\section{La genèse des circuits « Dracula, Vérité et Légende "}

Les agences touristiques qui proposent en premier aux touristes des programmes utilisant le thème Dracula sont, dans la seconde moitié des années 1960, anglaises et américaines. Néanmoins, selon une employée du comité d'organisation du département de propagande du ministère du Tourisme roumain que nous avons interviewée, ce thème ne semble pas préoccuper le tourisme roumain de l'époque, en raison peut-être d'une certaine méconnaissance ${ }^{7}$ du personnage de Bram Stoker à cette époque en Roumanie, mais aussi en l'absence d'un rapprochement clair entre ce personnage littéraire et une

5. Cet article s'appuie à la fois sur une enquête par entretiens, menée auprès des guides et d'autres acteurs du secteur touristique roumain de l'époque communiste et sur un travail d'archives (sur matériaux touristiques, monographies historiques, presse, almanachs, documents officiels du PCR). Pour rendre compte des usages du tourisme à l'époque communiste, cet article place la focale sur les producteurs d'un tourisme à thème Dracula en Roumanie. Or, il aurait été intéressant d'articuler cette analyse avec l'étude des motivations des touristes étrangers participant aux circuits. L'absence de cette analyse dans notre travail en constitue une limite.

6. Signalons le travail de Duncan Light (2007).

7. La nouvelle « Dracula » est traduite pour la première fois en roumain après 1989 (Light 2007). 
figure appartenant à l'histoire roumaine ${ }^{8}$. L'intérêt de ce thème pour le tourisme roumain se révèle véritablement au début des années 1970, quand l'agence américaine «General Tours » propose au ministère roumain du Tourisme un voyage intitulé « Flash sur Dracula : Une aventure en Transylvanie ${ }^{9}$, inspiré du programme $"$ Sur les traces de Dracula ${ }^{10}$ rédigé par Radu Florescu et Raymond McNally à la suite du succès de leur livre (Florescu et McNally 1972), qui associait explicitement le comte vampire au voïvode valaque. Le circuit de « General Tours » combine des spectacles dédiés au « vampire », et un tourisme patrimonial : des spectacles son et lumières sur le « tombeau du vampire Dracula », situé à proximité de Bucarest, sont ainsi associés à des visites d'un château fort bâti par Vlad l'Empaleur en Valachie. Ces circuits proposent ainsi une sorte de mise en spectacle d'hypothèses érudites avancées par les historiens R. Florescu et R. McNally. L'offre touristique de l'agence américaine est finalement rejetée par le ministère du Tourisme roumain en raison du label «vampire Dracula » attaché aux sites historiques liés à Vlad l'Empaleur et de la présentation de la Transylvanie comme terre de superstitions.

Néanmoins, l'idée d'une adaptation de ce thème fait par la suite son chemin dans le tourisme roumain. Un employé du ministère du Tourisme, qui restitue pour nous la genèse des circuits roumains, présente les premiers moments de la création d'un motif de « Dracula » en Roumanie comme un moment de doutes et de tâtonnements :

"On a eu, à ce moment-là, quand cette brochure-là y est arrivée (au ministère du Tourisme), un ministre du Tourisme, [...] qui nous dit (se référant au programme proposé par General Tours): « Messieurs, qu'est-ce que c'est que ce truc? » Eh bien, il avait évidemment pas lu "Dracula» (le roman de Bram Stoker), [...] Et nous, nous l'avons éclairé... Moi, je travaillais à l'époque au département de promotion extérieure, j'avais déjà lu ce livre, je savais... Et il nous dit : " [...] C'est quoi Dracula alors?" "Ah, Monsieur le ministre, c'est beaucoup de films, beaucoup de livres! " «Ah, oui ?! Mettez-vous alors à faire des expérimentations pour qu'on sache, nous aussi, de quoi il s'agit exactement! » (Entretien 2003, Bucarest).

Le ministère du Tourisme roumain se réapproprie ainsi l'idée et met en place à titre d'expérimentation deux types de circuits à thème Dracula. Si les deux circuits envisagés se proposent de faire suivre aux touristes le même trajet - de la capitale Bucarest à Brasov, ville située au pied des Carpates en Transylvanie, ils se différencient cependant par les récits transmis par les guides. Un premier circuit expérimental se centre sur la mise en récits des superstitions populaires roumaines - les croyances dans les «strigoi » (revenants) - tandis que le second s'attache à l'exposition des hauts faits de Vlad l'Empaleur. Le point commun de ces deux circuits réside dans la volonté du ministère du Tourisme roumain de distinguer fortement projet roumain et projet américain. Ainsi,

8. À part l'étude philologique des noms «Vlad l'Empaleur» et «Dracole», réalisée par G. Nandris (1959), qui suggère qu'il doit y avoir une raison dans l'association que B. Stoker a établie entre les deux, l'historiographie roumaine n'a pas produit, jusqu'aux années 1970, des travaux examinant explicitement le rapport entre la nouvelle de Stoker et l'histoire de Vlad l'Empaleur. Au début des années 1970, Dracula et Vlad l'Empaleur ne sont donc pas pensés ensemble en Roumanie.

9. En version originale Spotlight on Dracula: An Adventure in Transylvania, Brochure touristique, 1972. C'est nous qui traduisons.

10. En version originale, In Search of Dracula, c'est nous qui traduisons. 
pour le premier circuit, au motif du «vampire $»^{11}$ est opposée la catégorie folklorique roumaine de « strigoi »" ${ }^{12}$, et dans le second circuit, le voïvode Vlad l'Empaleur est censé tenir en respect le comte vampire Dracula.

C'est le second circuit fondé sur un discours se voulant historique qui va finalement être choisi par le ministère du Tourisme roumain. Intitulé « Dracula, Vérité et Légende », ce circuit finit par s'imposer à partir du milieu des années 1970 et il est promu par l'Office National de Tourisme Carpates (ONT), l'unique tour opérateur roumain à cette époque. Ces circuits agencent les récits des guides concernant la vie et le règne de Vlad l'Empaleur (les luttes contre les Turcs), et l'exposition des sites historiques présentés comme des traces du passage glorieux de l'Empaleur. La capitale de la Valachie à l'époque de l'Empaleur, et le château fort de Poienari, bâti, selon une légende, par Vlad l'Empaleur à l'aide de boyards ${ }^{13}$ de Targoviste deviennent " un lieu de mémoire » attestant de la continuité de l'histoire roumaine dans la longue durée. La liste des lieux choisis visités par les touristes met en évidence en outre une invention des traditions (Hobsbawm 1995) : un château transylvain, résidence de la reine Marie, épouse de Ferdinand de Roumanie, va être introduit dans le circuit, et présenté aux touristes comme le lieu de naissance de Vlad l'Empaleur, désigné aussi comme « Dracula historique », alors qu'il n'existe aucun document l'attestant. Cette invention s'inspire de l'imagination des touristes étrangers euxmêmes qui, visitant la Roumanie antérieurement et dans le cadre d'autres programmes, avaient trouvé une ressemblance entre ce château et le château décrit par Stoker comme le « Château des Carpates », résidence du vampire Dracula (Light 2007). L'historicité de Vlad l'Empaleur, telle qu'elle est présentée aux touristes au travers des récits des guides, est donc tissée à la fois de discours savants roumains, d'éléments imaginés, et de lieux historiques réels mais arrangés.

Comment comprendre le choix fait par les responsables du secteur touristique d'un circuit Dracula centré sur l'histoire héroïque du pays ? Replacer ce choix dans le contexte politique interne de l'époque et l'analyser en lien avec la vision américaine permet d'en éclairer les logiques.

\section{Quand l'histoire le dispute à la légende : deux versions d'un même motif}

Le choix du circuit roumain est fondé sur une volonté de se distinguer du circuit américain peut être mieux compris comme contrastant avec les significations attribuées au motif Dracula aux États-Unis. Toutefois, l'évolution du motif roumain de Dracula est redevable à la fois au contexte politique interne et aux usages roumains de la version américaine.

11. Pour une présentation du thème du vampire dans la littérature anglo-saxonne et de ses caractéristiques nous renvoyons au travail de J. Marigny (1993).

12. Dans le folklore roumain, on ne se sert quasiment pas du terme vampire pour désigner les revenants (Florescu et McNally 1973 : 169). D'autres termes sont employés : strigoi, moroi, etc. pour nommer les âmes des morts qui sortent des tombes durant la nuit.

13. Nobles roumains. Le terme « boyards » désigne l'aristocratie des pays orthodoxes. 


\section{Les versions occidentales de Dracula}

Un regard rétrospectif sur la littérature et la filmographie à succès autour du vampire Dracula produites en dehors de la Roumanie montre que ce motif a connu plusieurs versions au fil du temps.

La nouvelle « Dracula » de Bram Stoker, parue en 1887, appartient à la littérature fantastique, et s'emploie à donner à travers le personnage de Dracula une illustration du Mal universel qui hante les vivants, mais que ces derniers parviennent finalement à vaincre. Le récit se présente comme l'histoire d'un voyage que le jeune clerc de notaire, Jonathan Harker, entreprend en Transylvanie, en vue de négocier et de conclure une affaire immobilière. Selon les termes de son journal intime, il arrive en Transylvanie, région des « quatre races » réputée conservatoire des superstitions populaires, et découvre bientôt le secret du comte transylvain : c'est un mort vivant, qui ne laisse aucun reflet dans le miroir, et qui sort de son cercueil pendant la nuit pour assouvir sa soif de sang humain. Au terme de ses aventures, Jonathan Harker se fait aider par des spécialistes des vampires avec lesquels il transperce le cœur de Dracula de deux coups de poignards, pour délivrer sa fiancée du Mal qui s'était emparée d'elle. La fin de la nouvelle marque la victoire de la Vertu sur le Vice, du Bien sur le Mal, confortant ainsi la morale de cette période victorienne (Marigny 1993).

La même logique d'illustration d'un Mal universel est à l'œuvre dans la construction de la figure de Dracula consacrée par le cinéma des années 1930. Bela Lugosi, acteur d'origine hongroise, émigré aux États-Unis en 1921, incarnera avec succès Dracula (notamment dans le film de 1931, mis en scène par Tod Browning). C'est l'accent hongrois, la lenteur du phrasé, le visage pâle qui vont imposer dans les années 1930 la figure du vampire Dracula au cinéma à côté de celle du monstre Frankenstein.

Or, le traitement cinématographique et littéraire du vampire Dracula semble être renouvelé dans les années 1970, en même temps que paraît aux États-Unis l'ouvrage de deux historiens de l'Université de Boston, R. Florescu et R. McNally. La parution du livre « À la recherche de Dracula : une vraie histoire de Dracula et des légendes des vampires » (Florescu et McNally 1972) marque, du moins peut-on en faire l'hypothèse, le début de l'identification du personnage de «Dracula » de Stoker avec le voïvode valaque du $15^{\mathrm{e}}$ siècle. La présence dans l'œuvre de Stoker de références géographiques et historiques a en effet incité R. Florescu et R. McNally à se demander si cet auteur ne s'était pas inspiré de l'époque et du règne de Vlad l'Empaleur pour donner vie au personnage de Dracula. Dans leur recherche, les auteurs analysent conjointement les sources de Stoker, l'époque et le règne de Vlad l'Empaleur et les croyances populaires de Transylvanie. Ils montrent que Bram Stoker s'est fondé sur des sources « authentiques » pour créer le plus « terrifiant et célèbre des vampires ». Selon les deux historiens, les pratiques d'empalement de ses ennemis, attestées par des chroniques saxonnes du $15^{\mathrm{e}}$ siècle, seraient des indices probants de la cruauté de Vlad l'Empaleur.

Plusieurs textes littéraires, programmes touristiques, films ${ }^{14}$ documentaires ou fictions vont reprendre ultérieurement cette logique en retraçant la filiation historique du personnage stokerien et en la renforçant, en s'attachant à incorporer l'histoire de Vlad

14. Pour un aperçu de la filmographie sur Dracula, voir Florescu et McNally (1972) et la base de données du film mondial IMBD (Site Internet : http://us.imdb.com). 
L'Empaleur dans l'histoire du vampire Dracula ${ }^{15}$. D'où un triple glissement de la version que Bram Stoker a donnée sur Dracula. De l'image du vampire, on opère un déplacement vers l'image du voïvode valaque; des renseignements historiques arrangés, fournis par Stoker dans sa nouvelle ${ }^{16}$, on passe à des faits attestés par des documents historiques; des lieux imaginés de la Transylvanie ${ }^{17}$, on en vient à des lieux concrets, précis, repérables.

Ce triple déplacement produit une identification du vampire Dracula avec Vlad l'Empaleur, et celle de la Transylvanie (et, partant de la Roumanie) avec un territoire sauvage terrifiant. Ainsi, la version américaine, cristallisée dans les années 1970 permet de substituer à l'incarnation du Mal universel une incarnation historique du Mal, à partir du réinvestissement fictionnel d'un personnage historique.

\section{La version roumaine}

Alors qu'en Occident, le motif de Dracula des années 1970 se situe à la charnière d'une construction artistique et d'une entité historique, à la même époque en Roumanie communiste, une autre variante de ce motif est façonnée par les élites nationales qui s'attache, au contraire, à distinguer les deux. Les élites communistes roumaines élaborent une variante du motif «Dracula » qui consacre et consolide l'image de héros national de Vlad l'Empaleur, tout en s'attachant à mettre en évidence le caractère légendaire de l'ouvrage de Bram Stoker. La distinction entre Vlad l'Empaleur et Dracula, à l'œuvre dans la variante roumaine des années 1970, suppose donc la fabrication du premier en héros national et la négation historique de l'autre, relégué au rang de pure fiction.

Les circuits « Dracula, Vérité et Légende » seront donc là pour témoigner de la volonté de distinguer les deux figures, tout comme deux monographies historiques roumaines consacrées à Vlad l'Empaleur qui paraissent dans la deuxième moitié des années 1970, quelques années après la mise en place des circuits ${ }^{18}$. Dotée, dans cette période, d'un grand pouvoir de légitimation ${ }^{19}$, l'historiographie sur Vlad l'Empaleur doit donc fonder historiquement les pratiques touristiques à propos de Dracula pour montrer l'exemplarité du règne de Vlad l'Empaleur dans l'Histoire des Roumains. Dès lors, on constate un procès d'héroïsation de ce dirigeant par le pouvoir communiste. Pour accomplir ce travail d'héroïsation, l'historiographie communiste s'inspire largement d'une tradition historiographique et littéraire remontant au $19^{\mathrm{e}}$ siècle. Car, dès le début du $19^{\mathrm{e}}$, Vlad

15. Voir, par exemple, le film In search of Dracula (Aspekt Films, Suède, 1972), qui entrelace des aspects du folklore transylvain, de l'image de Vlad L'Empleur et de celle du vampire Dracula. Pour d'autres exemples à ce sujet, voir Miller (1997).

16. Pour des exemples, voir Miller (1997).

17. Chez Stoker, le Château de Dracula est situé dans le Défilé de Bârgau, alors qu'il n’y avait aucun château à cet endroit.

18. Une forte production iconographique, littéraire et cinématographique liée à Vlad l'Empaleur participe également, au milieu des années 1970 à ce processus.

19. Au $11^{\mathrm{e}}$ Congrès du Parti Communiste Roumain (PCR) de 1974, on approuve l'introduction d'un chapitre d'histoire dans le programme politique. Le passé national est ainsi converti en tradition du PCR et la révolution socialiste est prise pour l'aboutissement heureux d'une construction de la nation roumaine dont les origines se perdent dans les temps reculés des Daces et des Romains (Dragusanu 2002). Le réinvestissement idéologique du passé national passe par la résurgence et la construction des « héros nationaux » (Boia 1997; Dragusanu 2002). 
l'Empaleur est consacré comme un héros national roumain à travers ${ }^{20}$ le poème épique Tiganiada de l'érudit roumain Ion Budai Deleanu ou les écrits des historiens romantiques, de la génération de 1848 qui se servent de la lutte du voïvode valaque pour l'indépendance du pays pour éveiller la conscience nationale (Florescu et McNally 1973). La période communiste n'est donc pas la première à consacrer Vlad l'Empaleur en tant que « héros national ». Le mythe du voïvode accompagnait en effet la construction nationale roumaine du $19^{\mathrm{e}}$ siècle, dont s'inspire l'idéologie nationaliste de N. Ceausescu.

La monographie Vlad l'Empaleur (1979) de Nicolae Stoicescu ${ }^{21}$ insiste par exemple sur le combat du voïvode valaque pour la justice sociale et l'indépendance du pays. Dans l'avant-propos, l'auteur affirme que, dans cette période, la parution d'une monographie historique qui rende « à l'histoire la vraie personnalité de Vlad l'Empaleur », s'impose en raison des rapprochements qui ont été faits entre ce voïvode valaque et le vampire Dracula. Cette monographie s'assigne pour mission de démontrer que Vlad l'Empaleur est un « courageux voïvode de la Valachie, qui mérite pleinement une place d'honneur dans la galerie des grands héros du passé glorieux de la patrie » (Stoicescu 1979 : 6), alors que le vampire Dracula est le fruit d'une légende tissée au fil du temps par la littérature et les films. « Histoire » et «Légende », tel est le clivage que cet historien institue pour distinguer les deux figures.

Ainsi, pour démontrer le caractère historique de la figure illustrée par son ouvrage et en même temps le caractère légendaire illustré par les productions littéraires ou cinématographiques liées à Dracula, l'auteur met en avant l'idée que les matériaux propres au travail d'un historien se différencient sensiblement de ceux mobilisés par un écrivain ou un metteur en scène. Il creuse ainsi une opposition entre l'Histoire et la Littérature. Car si l'objectif premier de l'Histoire consiste, selon l'auteur, à « reconstituer » la 《vérité » historique, la Littérature demeurerait dans le registre de la «création ». Ces deux termes utilisés par l'auteur suggèrent une antinomie entre la restitution de faits disparus et la création, donc l'invention des faits. Il est porteur de la croyance positiviste voulant que les documents cités soient des preuves absolues de l'établissement de la vérité historique, d'où la fréquence d'expressions telles que «restituer», "sur la base des sources historiques », «toutes les sources narratives», «toutes les (sources) documentaires connues », « prouver », etc.

Pour étayer sa démonstration, N. Stoicescu propose une interprétation de la " cruauté » dont aurait fait preuve Vlad l'Empaleur différente de celle de ses collègues des États-Unis. Rappelons que Florescu et McNally avaient suggéré dans leur ouvrage que c'étaient les pratiques de punition des ennemis propres à Vlad l'Empaleur, qui, attestant d'une grande cruauté de ce voïvode, auraient décidé Bram Stoker à le convertir en vampire sanglant. Or, selon l'historien roumain, la cruauté du voïvode valaque doit être plutôt comprise comme

20. Les exemples sur cette question sont nombreux. Voir les travaux de Florescu et McNally (1973) et Buican (1991).

21. Un élément principal nous pousse à choisir cette monographie historique pour rendre compte de la voix officielle du PCR à l'égard de Vlad L'Empaleur : sa forte diffusion. L'ouvrage est publié à deux reprises en roumain $(1976,1979)$ et traduit en anglais (1978), ce qui porte à croire que vu la censure exercée durant cette période sur les publications et la forte l'idéologie officielle du PCR, il cadrait parfaitement avec cette dernière. On peut supposer que la monographie de Stoicescu s'est faite d'une certaine manière porte-parole de l'idéologie officielle et que, de la sorte, elle a participé d'une démarche historique de construction de l'Histoire nationale à l'époque communiste. 
une stratégie politique appropriée aux vicissitudes de son époque, où, pour parvenir à vaincre ses ennemis, il fallait avoir une main de fer. Ainsi, pour lui, comme pour nombre d'historiens roumains qui l'ont précédé22, si Vlad l'Empaleur était cruel, c'est que la situation politique l'y poussait et non qu'il se divertissait des souffrances des autres. L'interprétation que N. Stoicescu donne de la « cruauté » imputée à Vlad l'Empaleur part donc du constat d'une particularité expliquée par des conditions historiques générales (les conditions historiques difficiles nécessitent la cruauté), tandis que ses prédécesseurs manient le syllogisme pour en déduire que «Tous les hommes cruels sont des tyrans. Étant cruel, Dracula était un tyran ».

À partir de l'analyse de cette monographie, nous pouvons mettre en évidence trois dimensions de l'héroïsme dont serait doté Vlad l'Empaleur à l'époque communiste : des ressources personnelles; des stratégies politiques appropriées aux temps; une vision du rôle du dirigeant soucieux du bien commun, du peuple. Ces trois dimensions entrelacées transforment Vlad l'Empaleur de la qualité de «tyran sanglant» à sa consécration en « héros courageux ».

L'analyse de cette monographie historique permet de mieux comprendre les logiques à l'œuvre dans le choix d'un discours à connotations historiques comme support des circuits « Dracula, Vérité et Légende ». Si ces logiques sont propres au contexte politique communiste, caractérisé par une réécriture de l'Histoire, elles s'inscrivent aussi dans la longue durée de la construction de l'identité nationale roumaine.

Au terme de cette analyse des deux variantes du même motif, on constate que la version roumaine des années 1970 du motif Dracula s'attache à creuser l'écart, voire à s'opposer aux versions littéraires, historiographiques, touristiques, américaines de ces mêmes années. Mettant à profit l'analyse d'E. Goffman (Goffman 1975), on pourrait interpréter cette création en miroir inversé de la variante roumaine du motif de Dracula par rapport à la version américaine du même motif comme un retournement du stigmate représentant une vision négative de Vlad l'Empaleur et sa mise à profit à des fins économiques et politiques. On pourrait aussi penser que les guerres «picrocolines » autour de Dracula sont des micro-versions de la guerre froide qui mobilisaient tant les élites communistes que les responsables des « tours operators », friands d'exotisme pour tout ce qui se cachait derrière le rideau de fer. Cette hypothèse peut prendre sens dans l'analyse plus précise des enjeux politiques qui sous-tendent la conception et la mise en place des circuits roumains à propos de Dracula.

\section{La multiplicité des enjeux des circuits «Dracula, Vérité et Légende »}

La construction de la version roumaine de Dracula est le résultat synthétique d'enjeux politiques internes et externes à la Roumanie, dans lesquels objectifs patriotiques, territoriaux et de politique extérieure se croisent et se renforcent mutuellement.

\section{Objectifs patriotiques}

Petre Popescu ${ }^{23}$, guide touristique dans les années 1970, ayant participé à la conception des circuits «Dracula, Vérité et Légende », témoigne dans un entretien des objectifs

22. Pour une analyse des écrits historiographiques roumains sur Vlad L'Empaleur, voir Boia (1997).

23. Pour préserver son anonymat, le nom a été changé. 
patriotiques des circuits promus sous le communisme et du rôle pédagogique dont le guide était investi, témoignage qui corrobore les récits livrés par d'autres guides que nous avons interrogés. Tous soulignent l'importance accordée à la pratique du tourisme comme mission pédagogique, enracinée dans les valeurs nationales, laquelle impliquait d'enseigner l'histoire nationale aux touristes étrangers. Telle était l'injonction du PCR à l'égard des guides.

En outre, l'article 15 du programme de juillet 1971 confère au ministère du Tourisme des fonctions patriotiques: «Le ministère du Commerce intérieur, le ministère du Tourisme et les organes locaux du Parti et de l'État veilleront à ce que dans les espaces d'alimentation publique soit diffusée tout spécialement la création musicale de notre pays, en sélectionnant attentivement le répertoire étranger afin d'interdire les musiques qui expriment des courants décadents » (cité in Durandin 1994 :119). L'injonction de sélection des répertoires étrangers et la diffusion prioritaire des créations autochtones dévoilent une vision nationaliste du tourisme, envisagé comme mécanisme de réification de la fiction politique (Pinto 1986) que serait la nation communiste.

Dans un de ses ouvrages, Claude Karnoouh indique également qu' « une indéniable exigence d'identité nationale anime ces programmes de voyage organisés par des institutions attentives à la politique culturelle de l'État, sinon dirigées par des fonctionnaires chargés d'en contrôler la stricte application » (Karnoouh 1990 : 129). Pourtant, selon Karnoouh, le tourisme de masse est un phénomène trop récent dans le commerce international pour qu'on lui assigne le rôle de vecteur à part entière de diffusion de la propagande d'État; en revanche, en tant que savoir déjà ancien, antérieur au tourisme, le folklore en est, selon l'auteur, pleinement chargé. Néanmoins, l'analyse des circuits « Dracula, Vérité et Légende ", la restitution du point de vue des guides qui y ont travaillé et les documents officiels concernant le rôle que le PCR attendait du ministère du Tourisme montrent que, dans ce cas, le tourisme devient justement un moyen privilégié d'imposition de la politique identitaire, qui s'articule avec le travail de construction identitaire. À l'instar donc de l'historiographie, de la littérature, des gigantesques spectacles folkloriques et commémorations des « héros nationaux », le tourisme trouve sa place dans l'entreprise politique de construction de la nation communiste. Nous rejoignons, à travers cette interprétation du rôle du tourisme à l'époque communiste, le propos d'Anne-Marie Thiesse qui souligne que, d'une manière plus générale, le tourisme fait partie de l'entreprise de construction des identités nationales : « le tourisme «bon » ou " mauvais » relève d'une activité économique qui se fonde principalement sur le patrimoine national et le reconforme pour une consommation ludique » (Thiesse $2001: 255$ ).

\section{Objectifs de politique extérieure}

On l'a vu, les circuits roumains à thème Dracula s'adressaient prioritairement à un public occidental. Prendre en considération le public cible des circuits permet de comprendre que les circuits « Dracula, Vérité et Légende » répondent à une autre injonction du PCR : à travers eux, la Roumanie communiste entend diffuser son discours identitaire dominant en Occident. C'était donc peut-être une manière de marquer l'indépendance politique du pays et le refus de toute ingérence politique extérieure dans les affaires internes. Ce discours identitaire dominant se fonde sur la mise en valeur des valeurs autochtones en même temps qu'il marque une mise à l'écart des valeurs internationales, celles de l'Autre. 
Plusieurs éléments viennent à l'appui de cette hypothèse, en premier lieu les documents officiels. Les "Actes normatifs non publiés ${ }^{24}$ » mettent en évidence les stratégies des élites communistes à l'égard des séjours des touristes étrangers en Roumanie, faisant transparaître le rôle de vecteur de diffusion de la politique officielle attribué au tourisme à cette période. Le premier paragraphe de ces «Actes » souligne en effet que les mesures prises visent à faire « croître le nombre des touristes étrangers ${ }^{25}$ en Roumanie » et qu'elles ont pour «but la création de larges possibilités pour les touristes étrangers de connaître les réalisations du régime démocrate populaire et les beautés de la patrie». L'article 15 du programme de juillet 1971 cité plus haut soulignait par ailleurs déjà la volonté de sélectionner les répertoires musicaux nationaux au détriment du « répertoire étranger ».

Les déclarations publiques des responsables politiques communistes à l'égard des circuits «Dracula, Vérité et Légende " allaient elles aussi dans ce sens. La justification donnée par ces derniers à propos de la mise en place de ces circuits montre également que la construction de la variante roumaine du motif de Dracula émerge par le jeu d'opposition entre le «monde » et «notre héros »: « [...] Ce que nous voulons faire est de montrer au monde notre héros $[\ldots] »^{26}$. Le sens que nombre d'acteurs ayant participé aux circuits attribuent à la conception et à la mise en place de ces derniers par le régime communiste, dans les années 1970, conforte enfin notre hypothèse. Ainsi, lors de nos entretiens, Petre Popescu, guide touristique à l'époque, explique la décision du ministère du Tourisme de s'approprier le motif américain de Dracula en termes de «pragmatisme »: "Donc vous observez alors le pragmatisme de la société fermée de type Ceausescu ... le communisme, ça veut dire: 'Vous voulez Dracula?' 'Nous, on n'est pas d'accord avec lui, mais nous allons vous le donner! »

Les documents et déclarations citées se fondent tous sur une opposition recherchée entre « Nous » et «Eux ». Cette opposition, exprimée dans des contextes différents et à travers des voix différentes, a vocation de rendre patent le choix de l'état pour valoriser ce qui est reconnu comme appartenant à «Nous ». Appréhendés sous cet angle, les circuits s'assignent donc pour mission de défendre les valeurs autochtones contre celles venues d'Occident. Ils illustrent de ce fait un trait essentiel du régime communiste de Ceausescu: le choix du national contre toute influence externe. Et l'observation de Catherine Durandin à l'égard du repli sur soi comme caractéristique particulière du régime de Ceausescu vient appuyer cette interprétation. Selon elle, c'est le choix des valeurs nationales que Ceausescu établit comme ligne directrice de sa politique: «Ceausescu choisit le populaire, le national contre l'invasion extérieure qui ne peut être, en cette fin de décennie soixante, qu'occidentale, d'un Occident américanisé. [...] Ce premier geste fonde une réflexion et une politique culturelle qui s'installent dans l'autochtonisme et le protochronisme. K. Verdery définit, quant à elle, ce protochronisme comme la résurrection des arguments indigénistes de l'entre-deux-guerres fondant l'essence nationale. [...]

24. «Les actes normatifs non publiés. Décisions du conseil des ministres. 1960. En vigueur le $1^{\text {er }}$ janvier 1975. Conseil Législatif », document officiel secret du PCR, rendu public en février 2008 par l'Institut de l'investigation du communisme en Roumanie et publié sur le site http://media.hotnews.ro/media_serverl/ document-2008-02-11-2331512-0-strategia-turistica-comunistilor.pdf(consulté le 29 mai 2008).

25. Mise en évidence par l'auteur.

26. Déclaration parue dans la Tribune du 31 octobre 1978. 
Cette vague idéologique et culturelle [...] est significative d'un abandon des ouvertures occidentales au profit d'un repli défensif qui se confirme au début des années 1980 » (Durandin 1994 : 17).

\section{Objectifs territoriaux}

Un autre enjeu politique est également à l'œuvre dans la mise en place en Transylvanie des circuits «Dracula, Vérité et Légende»: la roumanisation de la Transylvanie. Sous Ceausescu, la construction de l'identité nationale passe en effet par une volonté d'imposition d'une politique d'homogénéité ethnique et d'unité nationale garantie par l'État ${ }^{27}$.

La Transylvanie est une région de pluralité ethnique et donc de mélange et mixité des valeurs roumaines, hongroises, saxonnes. Elle est également l'espace où les producteurs de la nation hongroise ont puisé le répertoire folklorique national hongrois (Thiesse 2001 : 281). Situer des circuits qui visent à diffuser l'exemplarité d'un héros national roumain dans une province anciennement hongroise permet de roumaniser la Transylvanie. Grâce à la répétition des pratiques et circuits touristiques et leur accès à un public étranger, la Transylvanie devient progressivement aux yeux de tous un territoire roumain, ni hongrois, ni saxon.

Le responsable de l'agence roumaine de tourisme dans l'Amérique des années 1970, Marin Victor ${ }^{28}$, un acteur important avec le guide Petre Popescu dans la mise en place des circuits «Dracula, Vérité et Légende », l'exprime d'ailleurs clairement lors des entretiens que nous avons faits avec lui. Il présente l'emplacement en Transylvanie des circuits comme une stratégie consciente des responsables politiques composant le Comité Central du PCR. Il est lui-même d'ailleurs convaincu de cette nécessité et affirme être parmi ceux qui ont contribué à faire prendre conscience aux élites communistes de cet important enjeu des circuits « Dracula, Vérité et Légende». La trajectoire sociale de Marin Victor permet de montrer que l'enjeu territorial des circuits roumains est le produit de la rencontre d'une politique étatique communiste d'homogénéité ethnique et d'unité nationale en Transylvanie avec des schémas de pensée d'acteurs chargés de mettre en place ces circuits.

Économiste de formation, Marin Victor est affecté, dans les années 1960, à l'ONT Carpates. Il gravit les échelons et occupe successivement le poste de conseiller, puis de directeur adjoint. Au début des années 1970, il devient responsable d'un bureau de tourisme roumain en Amérique. Ses parents lui ont inculqué l'ethos du travail «bien fait », et il se passionne progressivement pour ce secteur d'activité. En Amérique, il se donne une double mission : diffuser en patriote l'exemplarité de l'histoire nationale des Roumains, tout comme la variété des formes de reliefs présents en Roumanie, et en bon économiste, augmenter le nombre de touristes américains en Roumanie. Pour réaliser ces objectifs, il envoie régulièrement des programmes touristiques à de nombreuses institutions américaines, organise des conférences au siège de l'agence, noue des partenariats avec des revues réputées pour diffuser des publicités sur le tourisme en

27. Voir, par exemple, la déclaration de Nicolae Ceausescu lors de la Conférence Nationale du PCR, publiée dans Conferinta Nationala a Partidului Comunist Roman (Conférence Nationale du Parti Communiste Roumain) 1972, Éditions Politiques, Bucarest, pp. 74-75.

28. Pour préserver son anonymat, son nom a été modifié. 
Roumanie, et surtout il courtise une clientèle huppée, évaluée selon la profession et les revenus annuels, repoussant du même coup les potentiels touristes jugés démunis de ressources financières. Il refuse, par exemple, une collaboration avec le Reader's Digest, malgré l'insistance d'un de ses agents qui tente à plusieurs reprises de le persuader de diffuser une publicité sur les circuits touristiques en Roumanie, car il juge que le «public cible » du Reader's Digest constitue un public « pauvre », éloigné d'un de ses principaux objectifs : faire rentrer des devises au pays.

Selon lui la captation d'un public touristique instruit permettra également de transmettre la vision roumaine sur « l'histoire vraie » de l'Empaleur, et contribuera ainsi à phagocyter l'image de vampire qu'il a aux États-Unis, à la suite de certains films à thème Dracula et de travaux d'histoire. De surcroît, son installation aux États-Unis lui permet de suivre de plus près les films à thème Dracula : visionner ces films représente pour lui un travail «obligatoire» de documentation préalable pour bien comprendre comment s'y prendre pour attirer des touristes en Roumanie. L'analyse des films lui permet de constater que, dans l'histoire du cinéma, la figure cinématographique de Dracula est notamment incarnée par un immigré hongrois aux États-Unis, Béla Lugosi. Marin Victor explique alors avoir mené des recherches sur la biographie de l'acteur, et avoir constaté que, jeune, Béla Lugosi était engagé dans l'armée hongroise dirigée par Béla Kun, le chef du gouvernement communiste hongrois qui en 1919 a tenté de récupérer la Transylvanie ${ }^{29}$ par la force armée. Il voit donc dans l'incarnation cinématographique du vampire Dracula par un immigré hongrois, une stratégie symbolique hongroise visant à associer dans la conscience occidentale la Transylvanie à la Hongrie. Il témoigne en entretien avoir découvert une interview donnée par Béla Lugosi à une revue américaine, où l'acteur «a lancé l'idée que l'action (des films Dracula) se passe en Transylvanie, Hongrie ». En outre, en visionnant un film, il dit avoir vu l'image d'une carte d'Europe accrochée au mur sur laquelle la Transylvanie est représentée comme incluse dans les frontières hongroises. De plus, lors d'une polémique lancée par les historiens de l'Institut roumain d'Histoire sur le motif de Dracula dans le tourisme roumain, Marin Victor est convoqué d'urgence (il doit venir d'Amérique à Bucarest) devant le Comité Central du PCR pour justifier de l'importance de ces circuits. Le point fort de son argumentation était fondé sur l'espace territorial, comme il l'indique lors de nos entretiens : maintenir le thème Dracula dans le tourisme roumain permettait de lier symboliquement la Transylvanie à la Roumanie contemporaine : « Dracula, c'était pour moi plutôt une motivation publicitaire, car nous (au bureau de tourisme roumain aux États-Unis) avons commencé à utiliser l'image : 'Dracula-Roumanie-Transylvanie'. Vous savez, le marketing mix...».

Ainsi, les finalités politiques attribuées au motif de Dracula qui président à la construction de sa variante nationale dans la Roumanie des années 1970 sont diverses et articulées : enseigner la Nation sous une forme ludique aux touristes, diffuser en Occident la conception dominante de la Nation forgée par les élites communistes comme stratégie de refus de toute immixtion étrangère dans les affaires d'État, et enfin roumaniser la Transylvanie.

29. Le $1^{\text {er }}$ décembre 1918, lors de la grande Assemblée Nationale Constituante des Roumains, qui met en avant le principe du droit à l'autodétermination des peuples, la Transylvanie s'unit avec la Roumanie. Jusqu'à cette date, elle faisait partie de l'Empire Autriche-Hongrie. 


\title{
Conclusion
}

Pour conclure, la politisation du secteur touristique, que nous avons mise en évidence jusqu'à présent, entre vite en contradiction avec les attentes des touristes étrangers, en mal de héros fantastiques. C'est ainsi que progressivement, et Petre Popescu, ancien guide, en témoigne, l'écart se creuse entre les attentes des touristes étrangers « à la recherche du vampire Dracula » et l'offre touristique roumaine centrée sur le voïvode Vlad l'Empaleur. Selon lui, c'est une des raisons de l'échec du programme « Dracula, Vérité et Légende » qu'il retiendra pour ne pas répéter les mêmes erreurs lorsqu'après la chute du régime communiste, il crée une agence de tourisme proposant des circuits à thème Dracula.

Ré-agençant des savoirs issus de l'ouvrage de B. Stoker avec des informations données par des Instituts d'Ethnologie et d'Histoire roumains, fort des enseignements qu'il a tirés de son activité touristique antérieure, Petre Popescu a tous les atouts pour ajuster sa conception du tourisme aux attentes du public. Pour lui, le tourisme est pédagogie, spectacle et divertissement : «Je savais que je ne devais pas faire avec eux uniquement une leçon d'histoire ! Je devais les divertir aussi !» Pendant la période communiste, quand il était guide, il essaie déjà d'introduire deux éléments de « divertissement » dans le circuit touristique officiel : le thème du vampire et la région Bistrita (Défilé de Bârgau) où $\mathrm{B}$. Stoker avait situé l'action de son roman. Ainsi, selon ses dires, à la fin des années 1970, il se lance à son propre compte dans une activité touristique informelle visant à prolonger le circuit de l'Office National de Tourisme Carpates de Brasov, point final du circuit, jusqu'à Bistrita (au nord-est de la Transylvanie), région où Stoker avait situé son personnage, devenue ainsi « centre du monde draculien » :

\begin{abstract}
Moi, je savais que ce n'était pas pour l'Empaleur que les touristes venaient! Déception absolue! Personne ne revenait plus sur ce tour (il parle du circuit Dracula, Vérité et Légende). Et moi, quand je les emmenais à Brasov, une fois assis, le dernier soir, avec de la bière et du vin, je leur disais : "Moi, je sais pourquoi vous y êtes venus! Malheureusement, c'est ça le tour, sur Dracula historique! Je sais que vous n'êtes pas venus pour ça. Si vous voulez arriver là-bas (au centre du monde draculien), à quatre heures d'ici il y a le Défilé de Bârgau! Qui veut m'accompagner doit payer $180 \$$ pour trois jours et deux nuits! » Et ceux-ci qui acceptaient nommaient les trois jours les plus beaux jours de plusieurs années des vacances! Et j'introduisais le surnaturel aussi !! (Bucarest, 2003).
\end{abstract}

Ce «marché noir» touristique s'articule avec la construction d'un "Château de Dracula » dans Défilé de Bârgau, demandée par l'ONT de Bistrita et acceptée par la direction du Parti Communiste Roumain. Ainsi, le «Château Dracula » avec son cimetière, la " Crypte de Dracula » au sous-sol, et l'hôtel «Couronne d'or ${ }^{30}$ " à Bistrita vont couronner l'entreprise touristique Dracula des années 1980. L'accord du PCR peut paraître surprenant au vu de ses positions antérieures. On peut faire l'hypothèse que cet accord est le résultat des positions politiques occupées par certains dirigeants du département de Bistrita et des rapports de force des responsables de l'ONT départemental. Néanmoins, l'acceptation du PCR de faire construire un « monde draculistique » dans les frontières de la Roumanie montre finalement toute l'ambivalence (et que l'introduction

30. C'est le nom de l'hôtel où Jonathan Harker a séjourné pendant son voyage en Transylvanie. 
du château transylvain dans le circuit annonçait déjà) de la création du motif Dracula en Roumanie, même si cette ambivalence reste plus officieuse qu'officielle.

Mais la combinaison entre «pédagogie » et «divertissement» touristiques prend des formes plus subtiles dans les circuits «Dracula» promus par Petre Popescu après 1990. Les tours sont à présent structurés en quatre parties. Les deux premières parties concernent la visite de monuments historiques accompagnée d'un récit historique ou d'une mise en spectacle du récit historique par la réactivation de la mémoire vive. Véritables machines à remonter le temps, ces premières parties visent à donner le sentiment du passé. La première partie des circuits a lieu à Snagov, localisation du monastère bâti par Vlad l'Empaleur et, selon certains archéologues, où il fut enterré. La seconde se déroule dans un village situé auprès du château fort de Vlad l'Empaleur à Poienari. Des paysans habillés en costumes traditionnels se rassemblent le soir autour du feu et racontent les récits de la bravoure de Vlad l'Empaleur, histoires héritées de leurs ancêtres, lesquels auraient aidé le voïvode Valaque à échapper aux Turcs. La fréquentation touristique des « vrais descendants » de Vlad l'Empaleur est, dans la conception de Petre Popescu, une occasion pour les touristes d'observer les pratiques quotidiennes paysannes, puisque dès le matin, les autochtones vont au travail en " guidant les vaches vers les prairies ». La mise en spectacle de l'histoire est donc doublée de la mise en scène folklorique de l'activité agricole, élément fondamental dans la construction de "l'authenticité » à des fins touristiques. La troisième partie se déroule en Transylvanie sous forme d'un spectacle présenté, cette fois-ci, par un groupe d'acteurs amateurs locaux. Selon Petre Popescu, ce spectacle a pour vocation de «faire le passage vers la mythologie du vampire ». Or, le « surnaturel» mis en scène ici n'est plus le vampire des films ou du roman « Dracula », mais des motifs issus de croyances populaires du Moyen Âge. La quatrième partie des circuits a lieu enfin à Bistrita et dans le Défilé de Bârgau, lieux propices à la reprise du thème du « vampire Dracula ». Petre Popescu considère qu'il peut laisser libre cours à son imagination en ces lieux jugés dénués de toute trace d'histoire roumaine. Or, loin de reprendre le motif du « vampire » sanglant décrit par Bram Stoker, on a affaire à un « vampire » protecteur de la communauté, qui punit les membres enfreignant les normes sociales. Petre Popescu emprunte là la vision d'un vampire, élaborée par un ethnologue roumain avec qui il collabore. Le motif de Dracula, construit et reconstruit par Petre Popescu, parmi d'autres entrepreneurs roumains non abordés dans cet article, se trouve donc reconfiguré et sans cesse remodelé pour être ajusté aux attentes des touristes.

Ainsi, la version informelle du motif de Dracula à l'époque communiste et les formes qu'il prend dans le post-communisme mettent en évidence l'impact sur le public des arrangements entre vrai et faux, de la continuité entre folklore et archives, des parentés entre fiction et histoire. En jouant sur le registre du vrai ou faux, ou de la demi-teinte, l'entreprise touristique mobilise le désir d'imaginaire à des fins économiques.

\section{Références citées}

BoIA, Lucian, 1997. Istorie si mit in constiinta romaneasca (Histoire et mythe dans la conscience roumaine). Bucarest : Éditions Humanitas.

BOYER, Marc, 2002. « Comment étudier le tourisme ? », Ethnologie française, 91, pp. 393-404.

Buican, Denis, 1991. Dracula et ses avatars. De Vlad l'Empaleur à Staline et Ceausescu. La GarenneColombes : Éditions de l'Espace Européen. 
DRAGUSANU, Adrian, avril 2002. La commémoration des héros nationaux en Roumanie par le régime communiste de Nicolae Ceausescu (1965-1989), thèse en histoire, Faculté des études supérieures de l’Université de Laval, Canada.

DuRANDIn, Catherine, 1994. Histoire de la nation roumaine, Éditions Complexe (Questions au 20e siècle).

Florescu, Radu et Raymond T. MCNALly,

1972. In Search of Dracula: a True History of Dracula and Vampire Legends (À la recherche de Dracula : une vraie histoire de Dracula et des légendes des vampires). Connecticut: New York Graphic Society, Greenwich.

1973. Dracula: A Biography of Vlad The Impaler 1431-1476 (Dracula: une biographie de Vlad l'Empaleur 1431-1476). New York: Hawthorn Books.

Goffman, Erving, 1975. Stigmate. Les usages sociaux des handicaps. Paris : Les Éditions de Minuit.

Hoвsвawm, Eric, 1995. « Inventer des traditions », Enquête, 2, pp. 171-189.

ISTRATE, Ioan et Florina BrAn, 1996. Economia turismului si mediului inconjurator (L'économie du tourisme et de l'environnement). Bucarest : Éditions Economica.

Karnoouh, Claude, 1990. L'invention du peuple. Chroniques de Roumanie. Paris : Éditions Arcantere.

Light, Duncan, 2007. "Dracula Tourism in Romania. Cultural Identity and the State", Annals of Tourism Research, 43 (3), pp. 746-765.

Marigny, Jean, 1993. Sang pour le sang. Le réveil des vampires. Paris : Éditions Gallimard (Traditions).

Miller, Elisabeth, 1997. Reflections on Dracula. White Rock BC: Transylvania Press.

MikLos, Molnar, 1996. Histoire de la Hongrie. Paris : Éditions Hatier.

Muresan, Alexandra et A. Karen Smith, 1998. “Dracula’s Castle in Transylvania: Conflicting Heritage Marketing Strategies”, International Journal of Heritage Studies, 4 (2).

PINTO, Louis, 1986. «Une fiction politique : la Nation », Actes de la recherche en Sciences Sociales, 64, pp. $45-50$.

Storcescu, Nicolae, 1979. «Vlad Tepes ». Bucarest : Éditions Militara.

Thiesse, Anne-Marie, 2001. La création des identités nationales. Europe $18^{e}-20^{e}$ siècle. Paris : Éditions du Seuil.

Verdery, Katherine, 1991. National Ideology under Socialism. Identity and Cultural Politics in Ceausescu's Romania. Berkeley and Los Angeles: University of California.

VERDERY, Katherine, 2003. Socialismul Ce a fost si ce urmeaza, (tit. orig. What was Socialism, and what comes next?, Princeton University Press, 1996). Iasi: Editions Institutul European. 